\title{
Investigation on the Commercial Architectural Characteristics and formation of Wang Family Courtyard in Shanxi Province
}

\author{
Ning WANG \\ Nanjing Xiaozhuang University, Nanjing 211171, China
}

\begin{abstract}
Wang Family Courtyard is located in Jingsheng Town, Lingshi County, Shanxi Province. It is listed in the top of the first-batch famous historical and cultural towns issued by the former Ministry of Construction and the State Bureau of Cultural Relics. LIANG Sicheng, Famous architectural design Master, praises it as a "national building treasure"; many domestic experts and scholars call it as "imperial palace of the Chinese folk society, the greatest folk houses of China, and Forbidden Palace of Shanxi Province". For a long time, the studies about the buildings in Wang Family Courtyard mostly focus on the characteristics of the folk houses. In the long period of history, it paid more attention to the inheritance of the northwest natural conditions and social customs and architectural culture and its commercial buildings occupied a very low proportion, because of the traditional Confucian culture of valuing agriculture while despising commerce and the family's solid pursuit of resigning from official post. From a historical perspective, the commercial buildings in Wang Family Courtyard have their own characteristics. Therefore, the investigation on its history and characteristics is indispensable.

Keywords: Wang Family Courtyard; Commercial Buildings; Historical Investigation; Social Culture Investigation; Family Culture Investigation
\end{abstract}

\section{Introduction}

In Oct. 2003, Wang Family Courtyard, located in Jingsheng Town, Lingshi County, Shanxi Province, is listed in the top of the first-batch famous historical and cultural towns issued by the former Ministry of Construction and the State Bureau of Cultural Relics, because of its typical and unique folk living and local architectural style. In Jingsheng Town, Wang Family Courtyard, a place where the people whose family name was WANG lived together, is displayed in the tight gathering form and historical scenes because of the overall pattern (i.e. 9 gutters, 8 fortresses, and 19 lanes), in which a vivid living style is demonstrated. For these reasons, LIANG Sicheng, Famous architectural design Master, praises it as a "national building treasure"; many domestic experts and scholars call it as "imperial palace of the Chinese folk society, the greatest folk houses of China, and Forbidden Palace of Shanxi Province". For a long time, the studies about the buildings in Wang Family Courtyard are conducted mostly in terms of folk houses, while the research achievements related to the commercial buildings in Wang Family Courtyard are scare. Thus, an investigation on a few of commercial buildings inherited in Wang Family Courtyard is of important value.

\section{An overview of the buildings in Wang Family Courtyard}

Wang Family Courtyard, in Lingshi County, Jinzhong, Shanxi Province, is a significant representative of the northern folk houses in the area of Loess Plateau, but also a group of domestically well-preserved residential buildings constructed in the Qing Dynasty. It is built around slopes in accordance with the actual local conditions, in which the buildings reasonably change along with the landforms and are 
designed tightly with each other, and can play practical, strong, beautiful, and other functions. At present, Gaojiaya (the east courtyard) and Hongmenbao (the west courtyard) are its two major parts opened to the outside world. The two major parts used to be connected with horseshoe-shaped groove trail, but currently have a stone bridge stands between them. The whole village is surrounded by mountains and very skillfully conceived, in which the majestic momentum of the northern buildings is not only revealed, and also the beautiful and refined style of the southern buildings is contained in the finely crafted details. Its construction was gradually completed through the ruling periods of Kangxi, Yongzheng, Qianlong, and Jiaqing in the Qing Dynasty. Now, it became an excellent traditional architectural culture heritage and art treasure of China, and its large scale, grandiose momentum, subtle adornment, and clever conception are brightened with the traditional Chinese nation culture, temperament and verve, and romantic charm. Therefore, it is admired by people as "exquisite and unique human art works built with heaven's elements".

\section{The situation of the commercial buildings in Wang Family Courtyard}

Throughout the sceneries of Wang Family Courtyard, it was well-known in the whole country because of its life-based village houses mainly characterized by "kiln-lane-fortress". At that time, the social status of merchants was not high because the idea of "emphasis on agriculture at the expense of industry and commerce" prevailed in the feudal society, but the ancestors of Wang Family Courtyard reached their peak in the circles of officials and many of them were talented.

In the period of feudal society, the social productivity level was low and ordinary people regarded food and clothing as the purpose of survival, and also the profoundly circulating family idea of "when parents are alive, do not leave for a remote place" was very helpful to the stability of the agricultural labor force. The records about the business operation of villagers were rare in the historical inheritance though "merchants make profits from all places and become very rich" was written down in the Inscriptional Record of Wang Family filiation in Jingshen Village. Thus, the traces of the commerce as part of the residents' social life were not obvious.

The whole Wang Family Courtyard was built mainly for the Wang family members to live together, so residential architecture was primary in the construction pattern and commercial buildings occupied a very small proportion. In terms of today's Wang Family Courtyard preservation without really perfect buildings, the preserved representative commercial buildings within it are mainly divided into three types: storefronts around streets integrating residential and business activities - the most commercial parts; pawnshops concealed in the secondary road systems of the village; special commercial venues with a strong defense function.

In the storefronts existing currently in Wang Family Courtyard, the representatives were those to sell daily necessities at old Street 10 and old Street 1. It was said that old Street 10 gave top priority to the business of ready-made clothes, in which storefronts were built in front of houses. But these storefronts had been destroyed. Old Street 1 was preserved well and still operated using the model of "storefronts are built in front of houses". Only a few of pawnshops is preserved in today's Wang Family Courtyard. They were built at the end of the Qing Dynasty and the early period of the Ming Dynasty, but have been preserved up to now. Yuguo Convenience Pawnshop located in Gongxiu Lane was a representative of them. Pawnshop not only collected articles from people and also sold those that were not ransomed by owners. The architectural pattern was presented in a form of mixed stores and articles. Pawnshops around houses were very large and built close to slopes. In Wang Family Courtyard, there is a special 
building with a commercial, defense and early-warning function-Guangsheng Building with three differently functional layers connected by movable wooden ladder. In front of the original Guangsheng Building, there were storefronts: the first layer was for taking a rest and receiving guests in daytime; the second layer was for merchant's bedroom; the third layer was composed of short and narrow darkrooms for distance early warning and emergency.

The grand style of Wang Family Courtyard as folk house is beyond all doubts, but big differences are discovered from the investigation on the commercial buildings within it: commercial buildings occupy a very small proportion and this is a significant characteristic, and the construction scale (size) is generally not large; commercial buildings are mainly the limited small storefronts and small family workshops in the business of daily life necessities; commercial buildings are often close to the residential form and built in front of houses, but an independent building system as well as special characteristics does not develop, indicating commercial activities to be weak in the inheritance of the Wang Family.

\section{Multi-dimensional Investigation on the commercial buildings rare in Wang Family Courtyard}

In the large Wang Family Courtyard, there were many houses and a large residential population, why was a magnificent commercial building not derived in the long period of history? This was related to history, but also the feudal society's social and cultural constraints and the family's unique culture.

\subsection{Investigation from historical dimension}

Historically, Lingshi County was remote and surrounded by mountains, and it was in the state of not circulating goods and currency in a very long period, so business activities were not developed originally. Wang Family Courtyard, after 20 700 generations, has gradually formed its enormous scale famous at home and abroad. The changes of dynasties over hundreds of years made commercial buildings disappeared in the long period of history, and this was very normal. It was a rich and influential family place gradually formed in terms of family member gathering. For the sake of family security, maintaining the simplicity and limiting the external people were important precautionary measures. Therefore, commercial activities and buildings were generally arranged in the east and west streets of the ancient Jingsheng Town, but not directly in the courtyard of the Wang family members to live together.

\subsection{Investigation from social cultural dimension}

By referring to the historical documents about the business development of Shanxi Province, the vestiges about the Wang Family were not found at all in the records about Shanxi's wealthy and famous families, and the Wang Family seemed not to be a big business family. If the Wang Family was wealthy, how could its members construct such a castle-style building group? Obviously, it concealed its richness and the most fundamental reason lied in the feudal social cultural environment emphasizing agriculture and despising commerce. In the study, an interesting discovery is known: the ancestor of the Wang Family moved to Jingsheng Village in the period of the Yuan Dynasty and initially lived closely to Yongcui Lane, and he was only a peasant making tofu during the spare time. In the period of feudal society, however, the social productivity was low, agriculture was regarded as the foundation of the country, and business and businessman were always in the downstream position of the social classes. The phenomenon was gradually changed until the mid and late period of the Qing Dynasty. In view of the low position of commerce in the social ideology, today's Wang Family Courtyard buildings are those remains from the Qing Dynasty, and 
commercial buildings are difficult to be the key points.

\subsection{Investigation from family culture dimension}

As mentioned above, the development of the Wang Family's generations in several dynasties always followed the standard pattern of the feudal

flowing - "farming-business-reading-resign

from an official post", and also regarded the official career development of later generations as the ultimate goal. From historical materials, Wang Family gained fame and fortune in the ruling period of Shunzhi and Kangxi of the Qing Dynasty, and more than 50 Wang family members became an official. Of course, some of these people were admitted as an official through the imperial examination. In 1736-1908, 9 Wang family members became a successful candidate in the imperial examinations at the provincial level, and 4 became a scholar. Some were appointed to be an official because of donation or the existence of a powerful bureaucrats group. In the family culture cored at the pursuit of official career development, business was regarded as clearly as action taken by futile men, because the absence of commercial buildings is not a matter of accident in the inheritance of Wang Family Courtyard.

\section{Conclusions}

From the investigation on the characteristics of the commercial buildings in Wang Family
Courtyard and its origin, its value is not only embodied in the significance of architecture as grand art works in the history of folk houses, and its spirit and family culture is a rare legacy. Wang Family Courtyard, as a mirror of history, has left a deep imprint of history in the construction process and style and showed the shining architectural points of different periods. At the same time, today's Wang Family Courtyard has been greatly different from its initial appearance, but it reflects the shadow of history in all aspects, in which the previous and present life and the vicissitudes of life of the Wang Family members are mapped.

\section{Acknowledgement}

This paper aided financially by the scientific research project of Nanjing Xiaozhuang University, "Study on the History Cultural Inheritance of Wang Family Courtyard in Lingshi County, Shanxi Province" (No.2013NXY10).

\section{References}

[1] $\mathrm{Xi}$ ZHANG, Jie CHEN. Introduction to Wang Family Courtyard Using Pictures [M]. Taiyuan: shanxi Publishing Media Group (Shanxi Economic Publishing House), 2013: Preface.

[2] http://baike.so.com/doc/5327126.html

[3] Changhua WANG. Wang Family Courtyard: a Fossil of Farming Civilization [J]. The Silk Road, 2012

(15). 